\title{
Conflicto, salud y satisfacción: diferencias por etapa en parejas de la Ciudad de México
}

\author{
Yanitza Nicole Flórez Rodríguez ${ }^{1}$, Rozzana Sánchez Aragón², María Fernanda \\ Figueroa Peña ${ }^{3}$, Yamile Andrea Gómez Delgado ${ }^{4}$, Sonia María Rosero Díaz \\ del Castillo ${ }^{5}$ \\ Universidad de Nariño-México y Universidad Nacional Autónoma de \\ México-México
}

\begin{abstract}
Las relaciones atraviesan por diferentes situaciones que pueden generar inestabilidad y disgustos o conflictos entre los miembros de la pareja, que repercuten en ella favoreciendo la insatisfacción, frustración o hasta el término de la relación afectando en gran medida la salud y el bienestar de la persona. Por dicha razón, el objetivo principal fue conocer la relación entre los motivos e importancia del conflicto con la salud y la satisfacción con la relación. Para ello se trabajó con 240 personas (50\% mujeres y 50\% hombres), con edades comprendidas entre los 18 y 75 años que se encontraron dentro de una de las cuatro etapas del ciclo de la pareja: desarrollo, mantenimiento con hijos pequeños y grandes y disolución.

Palabras clave: conflicto, pareja, salud, satisfacción, ciclo vital.
\end{abstract}

\section{Conflict, Health and Satisfaction: Differences by Stage in couples from Mexico City}

The relationships go through different situations that can generate instability and upsets or conflicts between the members of the couple, which impact on it, favoring dissatisfaction, frustration or even the end of the relationship, greatly affecting the health and well-being of the person. Based on this, the objective of this study was to know the relationship among the conflict reasons and importance with health and satisfaction with the relationship. To this end, we worked with 240 people (50\% women and 50\% men), aged between 18 and 75

1 Licenciada en Psicología. Estudiante de posgrado en la Universidad de Nariño. Dirección postal: Calle Chichimecas 373, Ajusco. Ciudad de México 04300. Contacto: nicole.florez.r@ gmail.com. https://orcid.org/0000-0002-0298-001X

2 Doctora en Psicología. Profesora titular en la Universidad Autónoma de México, México. Dirección postal: Universidad Nacional Autónoma de México, Av. Universidad 3000, Del. Coyoacán, C.P. 04510. Contacto: rozzara@unam.mx. https://orcid. org/0000-0002-5952-8972

3 Magíster en Psicología. Profesora en la Universidad de Nariño, México. Dirección postal: Calle 18 Cr 50 Torobajo, Pasto. Contacto: mafefp@gmail.com. https://orcid. org/0000-0002-6427-345X

4 Magíster en Psicología. Profesora en la Universidad de Nariño, México. Dirección postal: Calle 9a No. 23-52 Obrero. Contacto: andreagomezdelgado21@gmail.com. https://orcid. org/0000-0003-0775-8917

5 Magíster en Psicología. Profesora en la Universidad de Nariño, México. Dirección postal: Calle 18 Cr 50 Torobajo, Pasto. Contacto: smroserod@gmail.com 
years who were in one of the four stages of the couple's cycle: development, maintenance with small children, maintenance with older children and dissolution.

Keywords: conflict, couple, health, satisfaction, life cycle.

\section{Conflito, saúde e satisfaçáo: diferenças por estágio em casais da Cidade do México}

Os relacionamentos passam por diferentes situaçôes que podem gerar instabilidade e desgostos ou conflitos entre os membros do casal, o que repercute em favor da insatisfação, frustração ou até mesmo do fim do relacionamento, afetando muito a saúde e o bem-estar da pessoa. Por esse motivo, o objetivo principal foi conhecer a relação entre os motivos e a importância do conflito com a saúde e a satisfação com o relacionamento. Para isso, 240 pessoas estavam empregadas (50\% mulheres e 50\% homens), com idade entre 18 e 75 anos, que estavam em uma das quatro etapas do ciclo do casal: desenvolvimento, manutenção com crianças pequenas e grandes. e dissoluçãa.

Palavras-chave: conflito, casal, saúde, satisfação, ciclo de vida.

\section{Conflit, santé et satisfaction: différences par stade chez les couples de Mexico}

Les relations traversent différentes situations qui peuvent générer de l'instabilité et des aversions ou des conflits entre les membres du couple, ce qui se répercute sur l'insatisfaction, la frustration ou même la fin de la relation, affectant gravement la santé et le bien-être de la personne. Pour cette raison, l'objectif principal était de connaître la relation entre les raisons et l'importance du conflit avec la santé et la satisfaction à l'égard de la relation. Pour cela, 240 personnes (entre 50 et $50 \%$ de femmes et $50 \%$ d'hommes) occupaient un des quatre stades du cycle du couple: développement, entretien avec des enfants petits et grands. et dissolution.

Mots-clés: conflit, couple, santé, satisfaction, cycle de vie. 
El Instituto Nacional de Estadística, Geografía e Informática (INEGI, 2016), muestran que en México el número de personas que se han divorciado ha aumentado con 139,807 en 2016 en comparación a 2013 que fueron 108,727; de cada 100 matrimonios, 22 se divorcian, lo cual es de gran preocupación, ya que cada año existen más parejas que le dan fin a su relación. Mirecki et al. (2013) consideran que la causa de mayor índice de divorcios son las elevadas tasas de conflicto, los mismos que se relacionan con enfermedades físicas y mentales, mortalidad, abuso de bebidas alcohólicas, baja autoestima, trastornos de alimentación, suicidio y afectaciones en la salud física, sexual y mental

Otros autores han referido como motivos de conflicto en la pareja a los desacuerdos en la forma de ver las cosas, deseos, ideas, valores, malos entendidos, celos, personalidad o historia de interacción diferente (Tapia et al., 2009); problemas relacionados con la insatisfacción sexual, toma de decisiones, falta de comunicación, actividad laboral, tiempo que se dedica a la pareja (Garrido et al., 2007), desigualdad en los ingresos económicos, infidelidad, incumplimiento de responsabilidades, egoísmo (Silva y Vázquez, 2016), manera de disciplinar a los hijos y tiempo que se les dedique, tareas domésticas, relaciones que se mantienen con la familia política, hábitos y costumbres, tiempo compartido como pareja, planes a futuro, afecciones y relaciones sexuales (Mora, 2015). Sin embargo, hay que decir, que es normal que dentro de las relaciones de pareja, surjan diferentes tipos de conflictos; ya que es en esta relación donde se vuelcan una serie de emociones, interacciones frecuentes y momentos decisivos que facilitan la experiencia de estos; creando un clima desagradable (Willi, 2002), lleno de tensiones, inestabilidad, duda, emociones y confusión que reta a los miembros de la diada a poner a prueba sus recursos tanto individuales como relacionales y que pueden llegar al punto de generar el término de la relación (Tapia et al., 2009). 
Además de la consecuencia mencionada, Mora (2015) señala que los conflictos producen en las personas involucradas: creencias erróneas, emociones negativas, objetivos y planes inalcanzables y sentimientos de inconformidad en ciertos aspectos de la relación —entre otras experiencias-. Es justamente, por la negatividad que caracteriza tanto al conflicto como a sus consecuencias del conflicto en la pareja, que lograr un manejo constructivo del conflicto, resulta fundamental para mantener una relación sana y enriquecedora (Álvarez Ramírez et al., 2015).

Existen diversos factores tanto sociodemográficos como psicológicos asociados con el conflicto en la pareja. Entre los primeros se encuentra el sexo de sus miembros, ya que se ha observado que los hombres y las mujeres perciben y enfrentan de modos diferentes las disputas, a partir de la manera en que ellos(as) piensan que es correcto. Otro factor es la duración de la relación, puesto que al conocer más a la pareja van surgiendo o haciéndose más evidentes las diferencias, los acuerdos cambian, los motivos de conflicto varían y el modo de pensar y percibir la vida también. Por último, la educación o forma de crianza que han recibido influye en cada uno de los miembros de la diada por las diferencias en cuanto a costumbres, tradiciones, experiencias pasadas, cultura y el lugar en el que crecieron (Rodríguez, 2015).

En cuanto a los psicológicos que se combinan con los sociodemográficos, la etapa del ciclo de vida de la pareja es también un factor que influirá en la experiencia del conflicto, ya que de acuerdo con el momento por el que esté pasando la pareja se le cambios, retos y problemas que generarán crisis, inestabilidad, desequilibrio, presiones y la necesidad de sopesar los recursos con los que se cuentan para así tratar de resolver lo necesario a la par que cumplir con ciertas obligaciones (Rodríguez, 2013). Por ejemplo, en la etapa de noviazgo o inicio de la vida juntos se presentan mayores conflictos con relación en las diferencias entre gustos, opiniones, intereses, celos, posesividad, costumbres, hábitos de alimentación o sueño (Arnaldo Ocádiz, 2001).

Por su parte, la etapa de la llegada de los hijos y el acoplamiento a responsabilidades de crianza se convierte en una etapa difícil por el ajuste requerido, generando disputas relacionados con manejo de las 
responsabilidades dentro y fuera de la casa, la crianza de los hijos, la dinámica de interacción con las familias de los miembros del vínculo romántico y comportarse irritables y desaliñadas. Asimismo, se limita el tiempo de convivencia e interacción entre la diada y el tiempo que se le dedica (Silva y Vázquez, 2016; Sánchez Aragón, 2018).

Cuando la pareja está a cargo de la formación de hijos adolescentes la dinámica tiene que ser reajustada en la pareja, ya que los hijos piden independencia y a la vez exigen más de la estructura familiar. Así, la pareja va poco a poco enfrentando los cambios que surgen ante la posible separación o salida de los hijos del hogar, lo que favorece conflictos relacionados con las actividades que se comparte en pareja, la atención que se le dedica, las responsabilidades que se tiene y falta de comunicación o expresión de sentimientos (Zazueta y Sandoval, 2013).

Finalmente, en la etapa de separación o divorcio la pareja experimenta diferentes tipos de conflictos relacionados con la comunicación y malentendidos, la sexualidad, la infidelidad y el dinero que pudieron dar pie a dicha situación (Silva y Vásquez, 2016), a la vez que una confusión de emociones negativas y estrés derivado de las diferencias entre los miembros de la pareja.

Es así como el conflicto dentro de la relación diádica el conflicto representa un aspecto normal e incluso necesario para poner a prueba los recursos de la pareja, pero al mismo tiempo, si no está bien manejado, puede poner en riesgo la relación (Sánchez Aragón, 2018) no solo en su estructura sino en su estatus emocional y psicológico. Al respecto, autores como Alzugaray y García (2015) indican que se ha encontrado que las parejas que mantienen frecuentes conflictos durante la relación presentan graves consecuencias en su salud física, psicológica y social, disminuyendo -además- de manera considerable su satisfacción con su pareja, ya que puede dañar tanto el estado emocional como la integridad de alguno de los miembros (Álvarez Ramírez et al., 2015; Antonio, 2015). La salud se entiende como el funcionamiento correcto de los procesos físicos, biológicos, sociales y afectivos que se ven influenciados por múltiples factores interrelacionados. Del mismo modo, se ha demostrado que los individuos casados gozan de una mejor salud física 
y mental que los que no lo están; esto solo cuando en la relación no se presentan de manera frecuente conflictos (García Higuera, 2002) que menoscaben la calidad de la relación.

Estudiar tanto la calidad como la satisfacción con la relación implica la identificación de las variables clave para entender cuáles son los factores que intervienen y mantienen la insatisfacción, la inestabilidad, el mal funcionamiento o el fin del vínculo de pareja. Pero habrá que empezar por definir a esta variable. Para Márquez Domínguez y Rivera Aragón (2010 en Flores Galaz, 2011) la satisfacción en la relación se concibe como la percepción subjetiva que los miembros de la diada tienen sobre su pareja y su relación, y la manera en la que cada miembro reacciona dentro de la relación, dependiendo de sus expectativas, necesidades y deseos con respecto al otro. Esta se basa en aspectos de tipo emocional, interacción, funcionalidad, felicidad, placer y estabilidad. En conjunto, la satisfacción se reconoce como un indicador de estabilidad y desarrollo de la relación, así como el funcionamiento general y específico de la pareja (Sánchez Aragón, 2016).

$\mathrm{Al}$ abordar a la satisfacción con la relación, es necesario reconocer que —al igual que en el conflicto — hay factores sociodemográficos y psicológicos vinculados a su experiencia. Así, por un lado y de acuerdo con Pérez Solís et al. (2016) los hombres tienden a estar más satisfechos con sus matrimonios que las mujeres, mientras que ellas se ven más afectadas por la edad y por la llegada de los hijos en comparación con ellos. Igualmente, se expone que los hijos tienen un efecto negativo sobre la interacción conyugal, especialmente cuando son pequeños o el hecho de tener muchos, ya que interfieren en la satisfacción con la relación, especialmente cuando los padres se encuentran en la fase de crianza. Asimismo, la edad es otro factor que se relaciona con la satisfacción de manera positiva, puesto que, a mayor edad de sus miembros, la satisfacción aumenta ya que el tiempo contribuye automáticamente al proceso de adaptación a su nuevo rol marital y familiar, aumentando su conciencia y buscando la solución a los problemas que presentan, así como asumiendo su responsabilidad y compromiso con la relación. Por otro lado, el afecto, el amor, la amistad, la intimidad, 
la comunicación, el interés, la satisfacción sexual, la duración y mantenimiento de la relación, así como su buen funcionamiento (Álvarez Ramírez et al., 2015) impactan en la satisfacción con la relación.

De esta manera, la satisfacción —al igual que el conflicto- en la relación de pareja se encuentra altamente ligada con la felicidad, el bienestar y la salud psicológica, lo que se demuestra en algunos estudios, en los que se encontró que a mayor satisfacción con la relación se percibe una reducción del estrés en las parejas que enfrentan algún tipo de enfermedad, asociándose con una mejor salud mental y menores niveles de depresión, emociones negativas y estrés (Arias Galicia, 2003; Oropeza Lozano et al., 2010; Rivero et al., 2011).

Con base en lo mencionado anteriormente, el objetivo principal de esta investigación fue: Conocer la relación entre los motivos de conflicto y su importancia con la salud y la satisfacción con la relación. Por otro lado, los objetivos específicos fueron (1) Identificar la magnitud en los motivos e importancia del conflicto, satisfacción con la relación y salud de personas con pareja por etapa del ciclo de vida e (2) Identificar las diferencias en motivos e importancia del conflicto y satisfacción con la relación de personas con pareja por etapa del ciclo de vida

\section{Método}

\section{Participantes}

Se trabajó con una muestra no probabilística por cuota (Hernández et al., 2006) de: 240 participantes (120 hombres y 120 mujeres) de la Ciudad de México distribuidas en cuatro etapas del ciclo vital de la pareja (30 parejas de cada etapa). Todos adultos de entre 18 y 75 ańos $(M=35.36$ y $D E=12.15)$ de los cuales 31 tuvieron una escolaridad de preparatoria (12.9\%), 108 licenciatura (45\%) y 101 de posgrado (42\%) al momento del estudio. Con respecto al tiempo de vivir juntos iba desde 6 meses hasta los 54 ańos. Su estado civil fue: el 12.1\% solteros, el $28.3 \%$ unión libre, el $44.2 \%$ casados y el $15.4 \%$ separados. 
Los criterios de inclusión a la muestra fueron: a) ser heterosexuales, b) mayores de 18 ańos, c) tener pareja, d) contar con una escolaridad mínima de preparatoria y, e) pertenecer a una de las cuatro etapas del ciclo de vida de la pareja siguientes:

1. Desarrollo (pareja a punto de casarse o a punto de empezar a vivir juntos, o recién casados o recién viviendo juntos (máximo 6 meses), luego de un noviazgo de al menos un año.

2. Mantenimiento con hijos pequeños (pareja casada o viviendo juntos con hijos de edades entre un mes a los 11 años (de 1 ańo a los 11 ańos).

3. Mantenimiento con hijos grandes (pareja casada o viviendo juntos con hijos de edades entre un mes a los 12 ańos en adelante (de 12 a 52 años).

4. Disolución (pareja casada o viviendo juntos a punto de separarse o divorciarse, o bien, recién separados o divorciados (máximo 6 meses).

\section{Instrumentos}

Escala de Motivos del Conflicto (Arnaldo Ocádiz, 2001) en su versión corta consta de 62 reactivos en formato de respuesta tipo Likert de cinco puntos de respuesta que indican grados de frecuencia (Nunca a Siempre). Estos reactivos se distribuyen en 14 factores: (1.) Educación de los hijos (6 reactivos y $\propto=.91)$, (2.) Ideología/intereses (6 reactivos y $\propto=.87$ ), (3) Actividades de pareja (6 reactivos $\mathrm{y} \propto=.83$ ), (4) Actividades propias (5 reactivos y $\propto=.85$ ), (5) Desconfianza (6 reactivos y $\propto=.80$ ), (6) Familia política (4 reactivos y $\propto=.74$ ), (7) Religión (3 reactivos y $\propto=.84$ ), (8) Personalidad (4 reactivos y $\propto=.83$ ), (9) Sexualidad (3 reactivos y $\propto=.83$ ), (10) Dinero/Irresponsabilidad (5 reactivos y $\propto=.79$ ), (11) Celos (4 reactivos y $\propto=.73$ ), (12) Adicciones (3 reactivos y $\propto=.56$ ), (13) Orden/Responsabilidad ( 4 reactivos y $\propto=.31$ ) y (14) Familia de origen (3 reactivos y $\propto=.74$ ). Se realizó un análisis factorial de componentes principales con rotación ortogonal (tipo varimax). La validez 
se obtuvo a través de un análisis factorial que explicó el $66.10 \%$ de la varianza y Alpha de Cronbach total de .86.

Escala de Importancia de los Motivos de Conflicto (Arnaldo Ocádiz, 2001), en su versión corta comprende 62 reactivos en formato de respuesta tipo Likert de cinco puntos que van desde Nada de importancia a Mucha importancia con respecto a cada afirmación. Estos reactivos se distribuyen en 10 factores: (1) Organización y funcionamiento familiar (12 reactivos y $\propto=.95$ ), (2) Adicciones/religión/celos (14 reactivos y $\propto=.93$ ), (3) Falta de atención (7 reactivos y $\propto=.92$ ), (4) Interés en la relación (7 reactivos y $\propto=.88$ ), (5) Personalidad (5 reactivos y $\propto=.79$ ), (6) Ideología/Intereses (4 reactivos y $\propto=.77$ ), (7) Orden/Desorden ( 4 reactivos y $\propto=.76$ ), (8) Desconfianza (4 reactivos y $\propto=.82$ ), (9) Familia (3 reactivos y $\propto=.80$ ) y, (10) Sexualidad (3 reactivos y $\propto=.83$ ). Se realizó un análisis factorial de componentes principales con rotación ortogonal (tipo varimax). La validez se obtuvo a través de un análisis factorial que explicó el 68.28\% de la varianza y Alpha de Cronbach total de .92.

Escala de Salud Física y Psicológica (Sánchez Aragón et al., 2017). Consta de 44 reactivos en dos secciones, la primera con 40 que se encuentran distribuidos en cinco factores que explicaron el $65.36 \%$ de la varianza y que arrojaron coeficientes de confiabilidad Alpha de Cronbach de moderados a moderados altos (.76 a .95): (1) Rol Emocional y Función Social, definido como el estado emocional del individuo y la manera en la que este afecta la interacción con las demás personas; (2) Función Física, definida como el desempeño óptimo para realizar actividades en las cuales intervenga un esfuerzo motor; (3) Rol Físico se encuentra relacionado con el desempeño físico de la persona y como afecta las labores diarias que realiza la persona; (4) Dolor Corporal, definido como una sensación molesta que limita la habilidad y la capacidad de la persona para realizar actividades cotidianas; (5) Vitalidad, la cual se encuentra relacionada con la energía que percibe la persona para desarrollar sus actividades dependiendo de sus funciones vitales. La segunda sección incluyó 4 reactivos en un solo 
factor que explicó el $55.1 \%$ de la varianza y cuyo coeficiente de confiabilidad fue de .73. El factor se nombró Salud General.

Indicadores de Satisfacción con la Relación. Consta de cinco reactivos con formato de respuesta tipo Likert de cinco puntos que indican grados de satisfacción con: "mi relación", "la atención que recibo de mi pareja”, el respeto que me brinda mi pareja”, las actividades que comparto con mi pareja" y "el cariño que recibo de mi pareja".

\section{Procedimiento}

Los instrumentos fueron aplicados en lugares públicos como sedes de universidades, cafeterías, así como otros establecimientos donde se pudieran encontrar participantes que cumplieran con los criterios de inclusión. Todos los participantes accedieron de manera libre y voluntaria, se les garantizó la confidencialidad y anonimato de sus respuestas.

\section{Análisis de datos}

En un primer lugar se realizó la prueba de normalidad Kolmogorov Smirnov, la cual mostró normalidad en los datos $(p>.05)$. Posterior a esto y con el fin de responder al primer objetivo dirigido a conocer la magnitud de las variables, se realizaron análisis descriptivos (medias y desviaciones estándar). Más adelante, se realizó un análisis de varianza de una vía para comparar a las cuatro etapas (desarrollo, mantenimiento con hijos pequeños, mantenimiento con hijos grandes y disolución) en términos de las variables bajo estudio. Por último, un análisis de correlación producto-momento de Pearson para examinar la relación entre ellas. Todo lo anterior mediante el uso del programa estadístico SPSS, versión 20.

\section{Resultados}

Respecto al primer objetivo los resultados indican que los motivos que más generan conflicto en las parejas son: la sexualidad (Frecuencia 
de las relaciones sexuales), seguidos por la desconfianza (Mi pareja no me dice todo), la educación de los hijos (Por el tiempo que les dedico a mis hijos) y celos (Sale con personas del sexo opuesto) y los que menos producen conflicto en la pareja son la religión (Creencias religiosas diferentes), las adicciones (Mi pareja fuma) y la familia de origen (Visitas a mi familia). No obstante, hay que mencionar, además, que los valores que se encontraron están por debajo de la media teórica.

Por lo que se refiere a la segunda variable de estudio se encontró que se le da mayor importancia a los conflictos que se producen por: la falta de atención (Sus actividades no permiten que tenga mucho tiempo para mi), desconfianza (Yo no le digo todo), organización y funcionamiento familiar (Forma en que disciplina a mis hijos) y los que menos importancia tienen son por el interés en la relación (Mi trabajo), ideología e intereses (Forma de pensar diferente) y orden/desorden (Mi pareja es exageradamente ordenada).

Con respecto a la salud se encontró que los participantes se sienten sanos (Estoy tan sano como cualquiera), con buena salud casi igual a la de hace un ańo y vitalidad (¿Que tanto se sintió calmado y tranquilo?). No presentan dolor corporal en gran medida (¿ha tenido un dolor por largos periodos de tiempo?), ni riesgo de enfermedad (Creo que mi salud va a empeorar). No se evidencia problemas en $\mathrm{Su}$ rol emocional y función social (¿hasta qué punto sus problemas emocionales han dificultado sus actividades sociales habituales con la familia, los amigos los vecinos u otras personas?), ni en su función física (¿Que tanto su salud actual le limita para hacer esfuerzos intensos tales como correr, levantar objetos pesados o participar en deportes agotadores?) y su rol físico (¿hizo menos de lo que hubiera querido hacer a causa de su salud física?).

Por último, sobre la variable satisfacción con la relación se evidenció que existe mayor satisfacción cuando se recibe un trato respetuoso y cariñoso por parte de la pareja y menos satisfacción con las actividades que se comparten con la pareja (ver Tabla 1). 


\section{Tabla 1}

Magnitud de motivos e importancia del conflicto, salud y satisfacción con la relación

\begin{tabular}{|c|c|c|c|}
\hline Escala & Factor & $M$ & $D E$ \\
\hline \multirow{14}{*}{$\begin{array}{l}\text { Motivos del } \\
\text { conflicto }\end{array}$} & Educación de los hijos & 2.17 & .92 \\
\hline & Ideología/Intereses & 1.88 & .68 \\
\hline & Actividades de la pareja & 2.10 & .72 \\
\hline & Actividades propias & 1.76 & .71 \\
\hline & Desconfianza & 2.23 & .78 \\
\hline & Familia política & 1.91 & .84 \\
\hline & Religión & 1.28 & .72 \\
\hline & Personalidad & 1.88 & .81 \\
\hline & Sexualidad & 2.84 & 1.29 \\
\hline & Dinero/Irresponsabilidad & 1.75 & .66 \\
\hline & Celos & 2.17 & .88 \\
\hline & Adicciones & 1.45 & .68 \\
\hline & Orden/Responsabilidad & 1.71 & .63 \\
\hline & Familia de origen & 1.50 & .78 \\
\hline \multirow{9}{*}{$\begin{array}{l}\text { Importancia } \\
\text { del conflicto }\end{array}$} & Organización y funcionamiento familiar & 2.59 & .80 \\
\hline & Adicción/Religión/Celos & 2.11 & .67 \\
\hline & Falta de atención & 2.80 & .93 \\
\hline & Desconfianza & 2.66 & 1.03 \\
\hline & Interés en la relación & 1.86 & .83 \\
\hline & Personalidad & 2.08 & .91 \\
\hline & Orden/Desorden & 1.73 & .80 \\
\hline & Ideología/Intereses & 1.80 & .84 \\
\hline & Familia & 2.13 & 1.15 \\
\hline
\end{tabular}




\begin{tabular}{llcc}
\hline \multicolumn{1}{c}{ Escala } & \multicolumn{1}{c}{ Factor } & $M$ & $D E$ \\
\hline Salud & En general, usted diría que su salud es & 3.47 & .88 \\
& Cómo diría que es su salud actual, comparada & 3.45 & .90 \\
& con la de hace un año & & \\
& Función física & 1.35 & .65 \\
& Rol físico & 1.25 & .54 \\
& Rol emocional y función social & 1.41 & .52 \\
& Vitalidad & 3.25 & .89 \\
& Dolor corporal & 2.04 & .70 \\
& Sentirse sano & 3.61 & .96 \\
& Riesgo de enfermedad & 1.93 & .92 \\
\hline Satisfacción & Con mi relación de pareja & 3.38 & 1.45 \\
con la & Con respecto a la atención que recibo de mi & 3.11 & 1.43 \\
relación & pareja & & \\
& Con el respeto que me brinda mi pareja & 3.57 & 1.47 \\
& Con las actividades que comparto con mi pareja & 2.92 & 1.43 \\
& Con el carińo que recibo de mi pareja & 3.51 & 1.48 \\
\hline
\end{tabular}

Los hallazgos del segundo objetivo se obtuvieron a partir de un análisis de varianza de una vía y muestran que existen diferencias estadísticamente significativas con respecto algunas variables en función de las cuatro etapas del ciclo de vida de la pareja; aunado a ello se realizó una prueba a posteriori de Scheffé, misma que indica en forma más precisa entre qué grupos se generan las diferencias.

Así, para el caso del conflicto, se encontraron diferencias estadísticamente significativas en la educación de los hijos, actividades de la pareja, actividades propias, desconfianza, familia política, sexualidad, celos, orden/responsabilidad y familia de origen. Es decir, las parejas en la etapa de disolución (etapa cuatro) manifiestan mayores problemas por la sexualidad, actividades propias, desconfianza, educación de los hijos, celos, actividades de la pareja, familia política, orden/responsabilidad y familia de origen en comparación con las otras etapas. Seguido 
de esta, la etapa de mantenimiento con hijos pequeños (etapa dos) muestran disputas por los celos, actividades propias, desconfianza, actividades de la pareja, educación de los hijos, familia política y familia de origen. Enseguida, en la etapa uno (desarrollo o inicio de la vida juntos) se evidencian problemas por la sexualidad, celos, desconfianza y actividades tanto propias como de la pareja principalmente. Por último, en la etapa tres (mantenimiento con hijos grandes) se observa un patrón similar al de la etapa dos (mantenimiento con hijos pequeńos) mencionada con anterioridad.

\section{Tabla 2}

Diferencias en los motivos conflicto por etapas de la relación de pareja

\begin{tabular}{|c|c|c|c|c|c|c|c|}
\hline & Factor & Et1 (a) & Et2 (b) & Et 3 (c) & Et 4 (d) & $F$ & $p$ \\
\hline \multirow{9}{*}{ 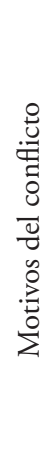 } & Educación de los hijos & $1.11(\mathrm{~b}, \mathrm{~d})$ & 2.18 & $2.03(\mathrm{~d})$ & 2.65 & 7.03 & .000 \\
\hline & Actividades de la pareja & $2.03(\mathrm{~d})$ & $2.02(\mathrm{~d})$ & $1.94(\mathrm{~d})$ & 2.41 & 5.45 & .001 \\
\hline & Actividades propias & $2.06(\mathrm{~d})$ & $2.20(\mathrm{~d})$ & $1.88(\mathrm{~d})$ & 2.76 & 5.76 & .001 \\
\hline & Desconfianza & $2.06(\mathrm{~d})$ & $2.20(\mathrm{~d})$ & $1.88(\mathrm{~d})$ & 2.76 & 16.52 & .000 \\
\hline & Familia política & $1.75(\mathrm{~d})$ & 1.95 & $1.65(\mathrm{~d})$ & 2.29 & 7.38 & .000 \\
\hline & Sexualidad & 3.04 & 2.66 & $2.50(\mathrm{~d})$ & 3.17 & 3.65 & .013 \\
\hline & Celos & 2.15 & 2.21 & $1.81(\mathrm{~b}, \mathrm{~d})$ & 2.53 & 7.23 & .000 \\
\hline & Orden/Responsabilidad & 1.66 & $1.62(\mathrm{~d})$ & 1.63 & 1.94 & 3.55 & .015 \\
\hline & Familia de origen & $1.33(\mathrm{~d})$ & 1.47 (d) & $1.33(\mathrm{~d})$ & 1.87 & 6.74 & .000 \\
\hline
\end{tabular}

En la variable Importancia del conflicto hubo menos diferencias estadísticamente significativas, únicamente se observaron en organización y funcionamiento familiar, orden/desorden y familia. Así, se halló que los participantes de la etapa cuatro (disolución) le dan mayor importancia los conflictos relacionados con la organización y funcionamiento familiar y la familia. Cuando el conflicto es por el orden o el desorden, las personas que se encuentran dentro de la etapa tres (mantenimiento con hijos grandes) le dan mayor importancia a este tópico, en comparación con los que se encuentran en la etapa dos (manteni- 
miento con hijos pequeños); y cuando pertenecen a la etapa uno (inicio de la vida juntos) le dan menos importancia a los conflictos por la organización y funcionamiento familiar.

\section{Tabla 3}

Diferencias en la importancia del conflicto por etapas de la relación de pareja

\begin{tabular}{llcccccc}
\hline & Factor & Et1 (a) & Et2 (b) & Et 3 (c) & Et 4 (d) & $F$ & $p$ \\
\hline Impor- & Organización y & 1.45 & $2.79(\mathrm{c})$ & $2.35(\mathrm{~d})$ & 2.90 & 10.92 & .000 \\
tancia & funcionamiento & (b, c, & & & & & \\
del con- & familiar & $\mathrm{d})$ & & & & & \\
flicto & Orden/Desorden & 1.85 & $1.47(\mathrm{c})$ & 1.88 & 1.73 & 3.38 & .019 \\
& Familia & 2.11 & 2.16 & $1.73(\mathrm{~d})$ & 2.53 & 5.10 & .002 \\
\hline
\end{tabular}

Para la variable de Salud las diferencias estadísticamente significativas entre los participantes de las distintas etapas del ciclo de vida de la pareja se hicieron notar prácticamente en todos los factores. Se pudo evidenciar que en la etapa tres (mantenimiento con hijos grandes) hay una percepción menos favorable de la salud en general, menos energía, vigor y fuerza (vitalidad) y una percepción de no sentirse saludable del todo (sentirse sano); mayores dificultades en ejecutar actividades que impliquen movimientos físicos (función física) y aflicciones en el cuerpo (dolor corporal), complicando el desarrollo de funciones diarias de la persona (rol físico) y mayor riesgo de sufrir algún tipo de enfermedad (riesgo de enfermedad). Para la etapa uno (desarrollo) se evidenció tener una mejor salud en general, mayor función física, vitalidad y menor riesgo de enfermedad. En la etapa dos (mantenimiento con hijos pequeños) se evidencian menos dificultades en su rol físico, rol emocional y función social y se sienten más sanos en comparación con las otras etapas. Por último, en la etapa cuatro (separación) se muestran más dificultades en su rol emocional y función social y menor dolor corporal, lo que los diferencia con las demás etapas del ciclo de vida de la pareja. 


\section{Tabla 4}

Diferencias en la salud por etapas de la relación de pareja

\begin{tabular}{|c|c|c|c|c|c|c|c|}
\hline & Factor & Et1 (a) & Et2 (b) & Et 3 (c) & Et 4 (d) & $F$ & $p$ \\
\hline \multirow[t]{8}{*}{ Salud } & $\begin{array}{l}\text { En general usted } \\
\text { diría que su salud es }\end{array}$ & 3.73 & 3.60 & $\begin{array}{c}3.03(\mathrm{a} \\
\mathrm{b}, \mathrm{c})\end{array}$ & 3.50 & 7.75 & .000 \\
\hline & Función física & 1.21 & 1.24 & $\begin{array}{c}1.67(\mathrm{a}, \\
\mathrm{b}, \mathrm{c})\end{array}$ & 1.28 & 6.71 & .000 \\
\hline & Rol físico & 1.15 & 1.12 & $\begin{array}{c}1.52(\mathrm{a} \\
\mathrm{b}, \mathrm{c})\end{array}$ & 1.22 & 7.18 & .000 \\
\hline & $\begin{array}{l}\text { Rol emocional y } \\
\text { función social }\end{array}$ & 1.40 & $1.27(\mathrm{~d})$ & 1.42 & 1.56 & 3.33 & .020 \\
\hline & Vitalidad & 3.49 (c) & 3.38 & 3.02 & 3.12 & 3.77 & .011 \\
\hline & Dolor corporal & 1.97 & 1.97 & 2.28 & 1.93 & 3.26 & .022 \\
\hline & Sentirse sano & 3.83 & 3.91 & $\begin{array}{c}3.10(\mathrm{a} \\
\mathrm{b}, \mathrm{d})\end{array}$ & 3.60 & 9.68 & .000 \\
\hline & $\begin{array}{l}\text { Riesgo de } \\
\text { enfermedad }\end{array}$ & $1.75(\mathrm{c})$ & 1.86 & 2.24 & 1.87 & 3.25 & .023 \\
\hline
\end{tabular}

Para finalizar, en todos los indicadores de Satisfacción se observaron diferencias estadísticamente significativas mostrando que en la etapa uno (desarrollo) se percibe mayor satisfacción con la relación, con la atención que se recibe con la pareja, el respeto, las actividades que se comparte y el cariño que se recibe por parte de la pareja en comparación con el resto de las etapas, principalmente con la etapa cuatro (separación del vínculo). En cuanto a las etapas medias (mantenimiento con hijos pequeños y mantenimiento con hijos grandes) la satisfacción se mantiene moderada alta de manera similar. 


\section{Tabla 5}

Diferencias en la satisfacción por etapas de la relación de pareja

\begin{tabular}{|c|c|c|c|c|c|c|c|}
\hline & Factor & Et1 (a) & $\begin{array}{l}\text { Et2 } \\
\text { (b) }\end{array}$ & $\begin{array}{l}\text { Et } 3 \\
\text { (c) }\end{array}$ & $\begin{array}{l}\text { Et } 4 \\
(\mathrm{~d})\end{array}$ & $F$ & $p$ \\
\hline \multirow{5}{*}{$\begin{array}{l}\text { Satis- } \\
\text { facción } \\
\text { con ... }\end{array}$} & mi relación de pareja & $\begin{array}{l}4.45(b \\
\text { c, d) }\end{array}$ & 3.98 & 3.72 & $\begin{array}{l}1.37 \\
(b, c)\end{array}$ & 163.40 & .000 \\
\hline & $\begin{array}{l}\text { la atención que recibo } \\
\text { de mi pareja }\end{array}$ & $\begin{array}{l}4.17(b) \\
\text { c, d) }\end{array}$ & 3.30 & 3.65 & $\begin{array}{l}1.32 \\
(b, c)\end{array}$ & 102.04 & .000 \\
\hline & $\begin{array}{l}\text { el respeto que me } \\
\text { brinda mi pareja }\end{array}$ & $\begin{array}{c}4.62(b \\
c, d)\end{array}$ & 4.05 & 4.03 & $\begin{array}{l}1.57 \\
(b, c)\end{array}$ & 141.16 & .000 \\
\hline & $\begin{array}{l}\text { las actividades que } \\
\text { comparto con mi pareja }\end{array}$ & $\begin{array}{c}3.82(b \\
\text { d) }\end{array}$ & 3.08 & 3.45 & $\begin{array}{l}1.35 \\
(b, c)\end{array}$ & 61.14 & .000 \\
\hline & $\begin{array}{l}\text { el cariño que recibo de } \\
\text { mi pareja }\end{array}$ & $\begin{array}{c}4.55(b \\
c, d)\end{array}$ & 4.10 & 4.00 & $\begin{array}{l}1.38 \\
(b, c)\end{array}$ & 184.48 & .000 \\
\hline
\end{tabular}

Para finalizar, los hallazgos con respecto al objetivo principal, el cual fue conocer la relación entre los motivos de conflicto y su importancia con la salud y la satisfacción con la relación evidencia correlaciones bajas y reducidas. Específicamente, al analizar el grado de asociación entre los motivos del conflicto con la salud se encontró que a más problemas por la manera en la que se educa a los hijos y la familia política, más afectaciones emocionales y dificultades para relacionarse con personas cercanas (rol emocional y función social). Cuando los conflictos se dan por la diferencia entre ideas, pensamientos y gustos (ideología/intereses), las actividades que se realizan y el tiempo que se dedica a estas (actividades propias), la religión que se profesa, el orden, la responsabilidad y la familia política de alguno de los miembros de la pareja más dificultades hay en su función física, rol físico y rol emocional y función social.

Cuando los conflictos se generan por las actividades que realiza la pareja y la desconfianza hay mayor afectación en el rol emocional y función física y menos vitalidad se percibe. Cuando el conflicto es por el dinero, la irresponsabilidad y las adicciones hay menor salud en 
general y percepción de sentirse sano y mayores problemas en la función física, rol físico y rol emocional y función social y dolor corporal. Al presentar disputas por los rasgos o características de personalidad mayor dificultad hay en el rol emocional y función social y una percepción de sentirse menos sano. Cuando el motivo del conflicto es por cuestiones sexuales (sexualidad) menos dificultades se presentan en su función física y si es por celos más se ve afectado el rol emocional y la función social (ver Tabla 6).

Con respecto a la importancia que se le da al conflicto, se observó que cuando es por adicciones, religión, celos, orden, desorden, ideología e intereses más afecciones en su función física, rol físico, rol emocional y función social, dolor físico y menos sensación de sentirse sano hay. Cuando es por la organización y funcionamiento familiar menos se siente que se goza de buena salud (sentirse sano) y más riesgo de enfermedad se reporta. Cuando se da importancia a los conflictos por familia y personalidad mayores emociones negativas se experimentan, menos interés por relacionarse y percepción de sentirse sano hay. Finalmente, cuando es por el interés en la relación menos salud en general se percibe y mayor riesgo en presentar algún tipo de enfermedad y afectaciones en sus funciones físicas, rol físico, rol emocional y función social se evidencia (ver Tabla 7).

En las correlaciones entre los motivos y la importancia del conflicto con la satisfacción con la relación (Tabla 8) se evidencia que cuando los motivos del conflicto son por la educación de los hijos, las actividades de la pareja, las actividades propias, la desconfianza, la familia política, los celos, el orden, la responsabilidad y la familia de origen menor satisfacción hay con la relación, con la atención que se recibe, el respeto, las actividades que se comparten y el cariño que se recibe. Cuando es por su personalidad menos satisfacción hay con el respeto y el cariño que se recibe y cuando es por el dinero y la irresponsabilidad se percibe menor satisfacción con la relación, con el respeto que se recibe y las actividades que se comparte con la pareja. 
Conflicto, salud y satisfacción / Flórez et al.

\section{Tabla 6}

Correlaciones entre los motivos de conflicto con la salud

\begin{tabular}{|c|c|c|c|c|c|c|c|c|}
\hline Factores & $\begin{array}{l}\text { En ge- } \\
\text { neral su } \\
\text { salud es }\end{array}$ & $\begin{array}{l}\text { Salud ac- } \\
\text { tual, com- } \\
\text { parada con } \\
\text { la de hace } \\
\text { un año }\end{array}$ & $\begin{array}{l}\text { Función } \\
\text { física }\end{array}$ & $\begin{array}{l}\text { Rol } \\
\text { físico }\end{array}$ & $\begin{array}{l}\text { Rol emo- } \\
\text { cional y } \\
\text { función } \\
\text { social }\end{array}$ & Vitalidad & $\begin{array}{l}\text { Dolor } \\
\text { corporal }\end{array}$ & $\begin{array}{c}\text { Sentirse } \\
\text { sano }\end{array}$ \\
\hline $\begin{array}{l}\text { Educación } \\
\text { de los hijos }\end{array}$ & - & - & - & - & $.198^{*}$ & - & - & - \\
\hline $\begin{array}{l}\text { Ideología/ } \\
\text { Intereses }\end{array}$ & - & - & $.195^{* *}$ & $.180^{* *}$ & $.220^{* *}$ & - & - & $-.164^{*}$ \\
\hline $\begin{array}{l}\text { Actividades } \\
\text { de la pareja }\end{array}$ & - & - & - & - & $.175^{* *}$ & $-.200^{*}$ & - & - \\
\hline $\begin{array}{l}\text { Actividades } \\
\text { propias }\end{array}$ & - & - & $.142^{*}$ & $.163^{*}$ & $.164^{*}$ & - & - & - \\
\hline Desconfianza & - & - & - & - & $.152^{*}$ & $-.165^{*}$ & - & - \\
\hline $\begin{array}{l}\text { Familia } \\
\text { política }\end{array}$ & - & - & - & - & $.166^{*}$ & - & - & - \\
\hline Religión & - & - & $.232^{* *}$ & $.254^{* *}$ & $.187^{* *}$ & - & - & - \\
\hline Personalidad & - & - & - & - & $.197^{* *}$ & - & - & $-.148^{*}$ \\
\hline Sexualidad & - & - & $-.150^{*}$ & - & - & - & - & - \\
\hline $\begin{array}{l}\text { Dinero/Irres- } \\
\text { ponsabilidad }\end{array}$ & $-.148^{*}$ & $-.131^{*}$ & $.210^{* *}$ & $.176^{* *}$ & $.160^{*}$ & - & $.145^{*}$ & $-.196^{* *}$ \\
\hline Celos & - & - & - & - & $.179^{* *}$ & - & - & - \\
\hline Adicciones & $-.146^{*}$ & $-.165^{*}$ & $.174^{* *}$ & $.245^{* *}$ & - & - & $.140^{*}$ & $-.219^{* *}$ \\
\hline $\begin{array}{l}\text { Orden/Res- } \\
\text { ponsabilidad }\end{array}$ & - & - & $.183^{* *}$ & $.182^{* *}$ & $.257^{* *}$ & - & - & - \\
\hline $\begin{array}{l}\text { Familia de } \\
\text { origen }\end{array}$ & - & - & $.162^{*}$ & $.174^{* *}$ & $.238^{* *}$ & - & - & - \\
\hline
\end{tabular}

Nota: $p<.05^{*}, p<.01^{* *}$ 


\section{Tabla 7}

Correlaciones entre la importancia de los motivos de conflicto con la salud

\begin{tabular}{|c|c|c|c|c|c|c|c|c|}
\hline Factores & $\begin{array}{c}\text { En } \\
\text { general } \\
\text { su } \\
\text { salud } \\
\text { es }\end{array}$ & $\begin{array}{l}\text { Salud ac- } \\
\text { tual, com- } \\
\text { parada con } \\
\text { la de hace } \\
\text { un año }\end{array}$ & $\begin{array}{c}\text { Función } \\
\text { física }\end{array}$ & $\begin{array}{c}\text { Rol } \\
\text { Físico }\end{array}$ & $\begin{array}{l}\text { Rol emo- } \\
\text { cional y } \\
\text { función } \\
\text { social }\end{array}$ & $\begin{array}{l}\text { Dolor } \\
\text { corporal }\end{array}$ & $\begin{array}{c}\text { Sentirse } \\
\text { sano }\end{array}$ & $\begin{array}{c}\text { Riesgo de } \\
\text { enferme- } \\
\text { dad }\end{array}$ \\
\hline $\begin{array}{l}\text { Organización } \\
\text { y funcio- } \\
\text { namiento } \\
\text { familiar }\end{array}$ & - & $.239^{* *}$ & - & - & - & - & $.183^{*}$ & $-.239^{* *}$ \\
\hline $\begin{array}{l}\text { Adicción/ } \\
\text { Religión/ } \\
\text { Celos }\end{array}$ & - & - & $.134^{*}$ & $.227^{* *}$ & $.174^{* *}$ & $.149^{*}$ & $-.171^{*}$ & - \\
\hline $\begin{array}{l}\text { Interés en la } \\
\text { relación }\end{array}$ & $-.165^{*}$ & - & $.148^{*}$ & $.178^{* *}$ & $.181^{* *}$ & - & $-.214^{* *}$ & $.151^{*}$ \\
\hline Personalidad & - & - & - & - & $.166^{*}$ & - & $-.143^{*}$ & - \\
\hline $\begin{array}{l}\text { Orden/ } \\
\text { Desorden }\end{array}$ & - & - & $.168^{* *}$ & $.150^{*}$ & $.147^{*}$ & - & $-.172^{* *}$ & - \\
\hline $\begin{array}{l}\text { Ideología/ } \\
\text { Intereses }\end{array}$ & - & - & $.143^{*}$ & $.166^{*}$ & $.211^{* *}$ & - & - & - \\
\hline Familia & - & - & - & - & $.177^{* *}$ & - & - & - \\
\hline
\end{tabular}

Nota: $p<.05^{*}, p<.01^{* *}$

Referente a la importancia del conflicto, cuando es por la familia, menos satisfacción hay con la relación, con la atención que se recibe, el respeto, las actividades que se comparten y el carińo que se recibe. Al darle mayor importancia al conflicto por interés en la relación menos satisfacción con la relación, con la atención y el respeto que se recibe por parte de la pareja existe y cuando es por la Organización y funcionamiento familiar y la falta de atención menos satisfacción con respecto a la atención y el respeto que brinda la pareja y las actividades que se comparte con la misma (ver Tabla 8). 
Conflicto, salud y satisfacción / Flórez et al.

\section{Tabla 8}

Correlaciones entre el motivo e importancia del conflicto con la satisfacción con la relación

\begin{tabular}{|c|c|c|c|c|c|c|}
\hline & \multicolumn{6}{|c|}{ Satisfacción con ... } \\
\hline & Factores & $\begin{array}{l}\text { mi rela- } \\
\text { ción de } \\
\text { pareja }\end{array}$ & $\begin{array}{l}\text { la aten- } \\
\text { ción que } \\
\text { recibo de } \\
\text { mi pareja }\end{array}$ & $\begin{array}{l}\text { el respeto } \\
\text { que me } \\
\text { brinda mi } \\
\text { pareja }\end{array}$ & $\begin{array}{l}\text { las activida- } \\
\text { des que com- } \\
\text { parto con mi } \\
\text { pareja }\end{array}$ & $\begin{array}{l}\text { el cariño } \\
\text { que recibo } \\
\text { de mi } \\
\text { pareja }\end{array}$ \\
\hline \multirow[t]{10}{*}{$\begin{array}{l}\text { Motivos del } \\
\text { conflicto }\end{array}$} & $\begin{array}{l}\text { Educación de } \\
\text { los hijos }\end{array}$ & $-.22^{* *}$ & $-.20^{* *}$ & $-.21^{* *}$ & $-.23^{* *}$ & $-.31^{* *}$ \\
\hline & $\begin{array}{l}\text { Actividades de } \\
\text { la pareja }\end{array}$ & $-.33^{* *}$ & $-.28^{* *}$ & $-.34^{* *}$ & $-.25^{* *}$ & $-.27^{* *}$ \\
\hline & $\begin{array}{l}\text { Actividades } \\
\text { propias }\end{array}$ & $-.32^{* *}$ & $-.28^{* *}$ & $-.28^{* *}$ & $-.28^{* *}$ & $-.29^{* *}$ \\
\hline & Desconfianza & $-.50^{* *}$ & $-.41^{* *}$ & $-.52^{* *}$ & $-.42^{* *}$ & $-.47^{* *}$ \\
\hline & Familia política & $-.29^{* *}$ & $-.28^{* *}$ & $-.26^{* *}$ & $-.29^{* *}$ & $-.30^{* *}$ \\
\hline & Personalidad & - & - & $-.14^{*}$ & - & $-.12^{*}$ \\
\hline & $\begin{array}{l}\text { Dinero/Irres- } \\
\text { ponsabilidad }\end{array}$ & $-.13^{*}$ & - & $-.12^{*}$ & $-.12^{*}$ & - \\
\hline & Celos & $-.24^{* *}$ & $-.21^{* *}$ & $-.27^{* *}$ & $-.15^{*}$ & $-.26^{* *}$ \\
\hline & $\begin{array}{l}\text { Orden/Respon- } \\
\text { sabilidad }\end{array}$ & $-.23^{* *}$ & $-.20^{* *}$ & $-.29^{* *}$ & $-.21^{* *}$ & $-.22^{* *}$ \\
\hline & $\begin{array}{l}\text { Familia de } \\
\text { origen }\end{array}$ & $-.20^{* *}$ & $-.28^{* *}$ & $-.21^{* *}$ & $-.19^{* *}$ & $-.26^{* *}$ \\
\hline \multirow{5}{*}{$\begin{array}{l}\text { Importancia } \\
\text { del conflicto }\end{array}$} & Organización y & - & $-.24^{* *}$ & - & $-.23^{* *}$ & - \\
\hline & $\begin{array}{l}\text { funcionamiento } \\
\text { familiar }\end{array}$ & & & & & \\
\hline & $\begin{array}{l}\text { Falta de aten- } \\
\text { ción }\end{array}$ & - & $-.18^{* *}$ & $-.15^{*}$ & - & - \\
\hline & $\begin{array}{l}\text { Interés en la } \\
\text { relación }\end{array}$ & $-.15^{*}$ & $-.14^{*}$ & $-.14^{*}$ & - & - \\
\hline & Familia & $-.20^{* *}$ & $-.24^{* *}$ & $-.14^{*}$ & $-.19^{* *}$ & $-.18^{* *}$ \\
\hline
\end{tabular}

Nota: $p<.05^{*}, p<.01^{* *}$ 


\section{Discusión}

Dentro del primer objetivo, el cual fue conocer la magnitud de los motivos del conflicto, importancia del conflicto, satisfacción con la relación y salud de las personas que se encuentran dentro de un vínculo romántico, se encontró que los motivos que más generan conflictos en la pareja son la sexualidad, la desconfianza, la educación de los hijos y los celos; expuesto a su vez por Flores Galaz et al. (2005) quienes señalan que las parejas suelen pelear por la frecuencia, intensidad y calidad de las relaciones sexuales, dado que culturalmente se mantiene un fuerte arraigo y valor al acto y desempeño sexual de la pareja. Igualmente, Arnaldo Ocádiz (2001) expresa que en ocasiones las formas de enseñar, educar o disciplinar difieren entre los padres intensificando las disputas. y con respecto a la desconfianza y los celos como razones que inician el conflicto, estos pueden deberse a que al ser parte de un vínculo romántico es normal sentir inseguridad y miedo de perder al ser amado (Rodríguez, 2015).

En lo que se refiere a los motivos que menos denotan conflictos en las parejas, los participantes puntuaron bajo en creencias religiosas, adicciones y familia de origen. Díaz Morfa (2003) afirma que las diferencias en las creencias que poseen las personas, siempre y cuando estas mantengan una postura madura y respetuosa, generan escasos conflictos en el nexo amoroso. Cabe resaltar que la mayoría de la muestra evaluada presenta nivel académico alto, que podría estar relacionado con una menor religiosidad (Aguilera Mochón, 2005; WIN/GIA, 2015) y por consiguiente con menores diferencias la respecto.

A su vez, presentar afición o dependencia a consumir sustancias psicoactivas no afecta en gran medida la relación de pareja; lo que contrasta con lo manifestado por Garrido et al. (2002) quienes encontraron que un detonante del conflicto es este tipo de conductas, dado que afectan y decrecen la confianza, la comunicación, el compromiso y la satisfacción dentro de la relación; o como lo mencionan Orgilés y Piñero (2006) el consumo de sustancias como alcohol o cigarrillo llegan a afectar a las partes cercanas al consumidor, disminuyendo su autoes- 
tima, estabilidad emocional y seguridad hacia él/ella o su compañero/a. Esto quizá se deba a que la media obtenida fue baja (1.45).

De igual forma, el tema de la familia de origen generó bajo conflicto en el vínculo diádico. Si bien, cuando dos personas deciden estar e iniciar una vida en conjunto, son los mismos los que dirigen la manera en la que convivirán, no obstante, se creará una conexión con la familia de cada miembro, trayendo consigo un factor de integración o desintegración en el vínculo romántico (Carreño Meléndez y Morales Carmona, 2016), considerando que cada familia tiene su propia historia y tradición (Ruiz, 2008).

Con lo que respecta a la segunda variable de estudio se encontró que se le da mayor importancia a los conflictos que se producen por la falta de atención, desconfianza, organización y funcionamiento familiar, lo que contrasta la información de Isaza (2011) que manifiestan que los celos, la infidelidad y el trato grosero o violento son motivos de mayor importancia en la mayoría de las relaciones, puesto que perjudica directamente la estabilidad y la satisfacción con la relación.

Los motivos que menos importancia tienen son por el interés en la relación, ideología y orden/desorden, ya que estos tipos de conflictos se generan usualmente en los primeros meses de reconocimiento, convivencia y adaptación. No obstante, Rodríguez (2015) sustenta que los motivos con mayor importancia son aquellos en los que la pareja no les brinda la atención o el tiempo que el otro considera necesaria para la relación, así como también compartir actividades o gustos afines que permitan el fortalecimiento del vínculo y la intimidad.

En términos de la salud de los participantes, esta es buena y vigorosa y no presentan inconvenientes en su salud emocional y la manera en la que conviven con las personas que les rodean, lo que tiene conexión con estudios sobre la salud y la esperanza de vida en México que explican que la esperanza de vida de la población ha aumentado de 63 años en 2013 a 65.8 años en el 2015, lo que se traduce en un incremento de 2.8 años (SIDSS, 2015). Aunque en los últimos ańos la consecuencia de los cambios que ha experimentado la población en cuanto a los estilos de vida, la alimentación de alta densidad energética, 
el consumo de tabaco y drogas, la violencia - entre otros aspectoshan puesto en peligro a la población mexicana, incrementando el riesgo de padecer una enfermedad crónico-degenerativa a edades tempranas (Soto Estrada et al., 2016).

Sobre la variable satisfacción con la relación se evidenció que existe mayor satisfacción en cuanto al trato respetuoso y carińoso por parte de la pareja y menos satisfacción con las actividades que se comparten, lo cual tiene gran lógica, ya que cuando la persona percibe un trato agradable, respetuoso y carińoso, se sienten más satisfechos con su relación y con el ser amado (Wieden, 2018). Sin embargo, cuando la pareja no dedica el tiempo suficiente, se tiene como resultado una menor satisfacción y estabilidad en el vínculo (Flores Galaz, 2011; Romero et al., 2017).

Los hallazgos del segundo objetivo evidenciaron que en la etapa de disolución o rompimiento del vínculo diádico se generan mayores conflictos por la educación de los hijos, actividades de la pareja, actividades propias, desconfianza, familia política, sexualidad, celos, orden/ responsabilidad y familia de origen en comparación a las otras etapas de la vida de la pareja. Esto puede deberse a que cuando se produce la separación, se intensifican las razones de conflictos, en vista de que la persona experimenta un sinfín de sentimientos, temores, percepción hacia el otro miembro y cogniciones que le generan malestar (Rodas López, 2018). Aunado a lo anterior, en México, hombres y las mujeres creen que las relaciones de pareja deben llegar a ser satisfactorias para lograr que la relación funcione, evitando de alguna forma el conflicto. Sin embargo, cuando es difícil solucionar los problemas o comunicarse asertivamente con el otro, prefieren darle fin a su relación (Flores Galaz, 2011).

A su vez, en los resultados se logró evidenciar que las parejas a cargo de hijos pequeños siguen en la lista de la etapa que más conflictos presentan, con problemas por celos, actividades propias, desconfianza, actividades de la pareja, educación de los hijos, familia política y familia de origen. Lo mencionado anteriormente puede deberse a que en esta etapa se enfrentan muchos cambios, que pueden generar inestabilidad y desajuste en la dinámica de la relación que se había construido hasta el 
momento (Hidalgo y Menéndez, 2003; Ramírez, 2004; Ripoll Núñez et al., 2013), trayendo consigo conflictos alrededor de la diada y su interacción, como por ejemplo, el tiempo que se dedica a la pareja, con relación al tiempo libre que se tiene ahora por las responsabilidades que genera criar a los hijos o la falta de esto, puede traer consigo desconfianza o celos también (Ramírez, 2004).

Asimismo, se evidencian dificultades con la familia política, que puede deberse a que al llegar a conformar nuevos vínculos con las familias de ambos no siempre la convivencia llega a ser buena, debido a factores como la afinidad, la influencia que ejerce, la ideología, etc. Igualmente, cuando las personas se encuentran en la etapa de enseñanza y crianza de los hijos, las familias de ambos desean ser partícipes de dicha crianza, a través de recomendaciones o consejos, generando en ocasiones, malestar entre ambos o al menos una de las partes (Carreño Meléndez y Morales Carmona, 2016). Cabe señalar que se encontraron patrones similares en los participantes que conformaron la etapa de mantenimiento con hijos grandes, lo que podría afirmarse que estas dos etapas se comportan muy similar, puesto que la crianza de los hijos sin importar la edad incide en la dinámica relacional (Hidalgo y Menéndez, 2003).

Pero cuando los participantes se encuentran dentro de la etapa del inicio de la vida juntos, se evidencian problemas por sexualidad, celos, desconfianza y actividades tanto propias como de la pareja. Estos hallazgos se apoyan en Isidro y Peńil (2014) quienes encontraron que los motivos que más generan conflicto son la infidelidad, los celos y la desconfianza puesto que al irse generando la mutualidad entre la pareja y con ello la noción de "nosotros", los miembros de la pareja sienten el riesgo de perder lo que en ese momento resulta importante. No obstante, lo observado en esta investigación se contrapone con lo observado por Sánchez Aragón (1995) quien dice que la etapa de inicio la frecuencia de los conflictos es menores, puesto que la pareja se halla en la cúspide del enamoramiento, la intimidad y la pasión.

En cuanto a la variable importancia de los motivos del conflicto se halló que los participantes de la etapa de disolución le dan mayor 
importancia a los conflictos relacionados con la organización y funcionamiento familiar, lo que puede deberse a que cuando se inicia la separación entre los cónyuges, la dinámica familiar se quebranta o se dańa, afectando a las personas que lo conforman; buscando nuevas alternativas para integrarse a una nueva dinámica familiar (Sanmartín, 2014).

Cuando el conflicto es por el orden o el desorden, las personas que se encuentran en la etapa con hijos grandes le dan mayor importancia, que concuerda con lo mencionado por De la Espriella (1995) que expone que en la etapa en que la pareja tiene hijos adolescentes o jóvenes los conflictos suelen darse por tópicos no tan significativos como limpiar el cuarto o sacar la basura. Lo que indica que no necesariamente este tipo de conflictos se genera entre las conductas de los miembros de la pareja, sino que muchas veces interviene la intercomunicación y el control con los hijos. En contraste, las parejas que se encuentran en la etapa con hijos pequeños les dan menos importancia a dichos conflictos ya que mantienen mayor control en las conductas de sus hijos, trayendo orden en la dinámica familiar. Finalmente, los participantes dentro de la etapa de desarrollo les dan menos importancia a los conflictos por la organización y funcionamiento familiar, lo que puede deberse a que al no encontrarse dentro de una relación con hijos no logran experimentar dificultades relacionadas con el cuidado y la responsabilidad de la crianza (Arnaldo Ocádiz, 2001).

Con respecto a la variable Salud, se evidenció que los participantes dentro de la etapa de mantenimiento con hijos grandes tienen menos vitalidad, energía, sensación de sentirse sanos y mayor dolor en su cuerpo y riesgo de presentar o desarrollar algún tipo de enfermedad. Lo que podría deberse a que usualmente las parejas con hijos grandes comienzan a envejecer y presentar mayores dificultades en su salud y la manera en que esta afecta en sus funciones diarias (Peńa, 2010), lo que se complementa con lo seńalado por De la Espriella (1995) quien menciona que los padres definen esta etapa como llena de preocupaciones y estrés, por las situaciones que se enfrentan con los hijos y la salida de los mismos del hogar. 
En la etapa dos, en donde la pareja se encuentra a cargo de hijos pequeños, suelen presentar menos dificultades en las funciones físicas, sociales y emocionales, además de que se manifiestan mucho más sanos. Esto se contrapone con lo que manifiestan Hidalgo y Menéndez (2003) ya que ellos dicen que en esta etapa existe mayor agotamiento físico y menos posibilidades de interacción por lo que conlleva estar a cargo de hijos de poca edad.

Para la etapa de separación o rompimiento del vínculo romántico se evidencia mayores dificultades en sus funciones emocionales y sociales, similar a lo que manifiesta Sanmartín (2014) quien expone que las personas en este tipo de situaciones experimentan emociones negativas como depresión, ansiedad o soledad, que suelen afectar el desempeño normal de la persona y su interacción con el medio que la rodea. Sin embargo, esto dependerá mucho de las razones y términos en los cuales la disolución se está dando, así como de las estrategias de afrontamiento que utilice, entre otros aspectos (Smith y Clark, 2017).

Ya para la variable Satisfacción con la relación, se observó que en la etapa de desarrollo hay mayor satisfacción con diferentes aspectos de la relación, lo que se encuentra en concordancia con lo que manifiestan Rivera et al. (2011) que sustenta que en esta etapa se suele realizar una evaluación positiva acerca de lo que se comparte con la pareja; a diferencia de las personas que deciden terminar su relación, ya que evidencian muchos más aspectos negativos y desfavorables de la relación que cosas por las que seguir junto a la pareja (Pérez Solís et al., 2016). No obstante, también puede deberse a que cuando se llega al punto de la separación se experimentan emociones negativas hacia la persona y la relación, impidiendo reconocer aspectos favorables de la misma (Ramírez, 2004; Sánchez Aragón, 2018).

Para el objetivo principal, el cual fue conocer la relación entre los motivos de conflicto y su importancia con la salud y la satisfacción con la relación, se logró observar que existen afectaciones e implicaciones negativas en la salud tanto física como emocional ante conflictos dentro de la relación de pareja; a pesar de que encontrarse en una relación romántica es un factor protector para la salud y el bienestar del 
individuo como lo manifiestan Alzugaray y García (2015). Esto puede deberse a que no es suficiente tener una relación de pareja para tener salud, sino que su calidad resulta más determinante. Así, la frecuencia con la que se presenten los conflictos y la importancia que se les da, incrementa las molestias y afectaciones en la salud física, emocional, el rol social, el dolor corporal y el riesgo de enfermedad. Como por ejemplo, a más problemas por la manera en la que se educa a los hijos, la familia política, celos y la personalidad más afectaciones emocionales y dificultades para relacionarse con personas cercanas, debido a que como se mencionó anteriormente la familia política puede ser un causal de enfrentamiento en el ámbito de la pareja con temas relacionados con la forma de ser de cada persona, el tipo de crianza que se imparte a los hijos, los roles que se han establecido dentro de la nueva familia (Hernández, 2012), trayendo consigo decaimiento y distanciamiento con la familia, amigos, vecinos o hasta con la pareja.

Cuando los conflictos se dan por la diferencia entre ideas, pensamientos y gustos, las actividades que se realizan, la religión, el orden, la responsabilidad, la familia política, el dinero y las adicciones más dificultades hay en su Función física, Rol físico y Rol emocional y función social. Una posible explicación es que, al no existir afinidad entre los miembros con respecto a su ideología, gustos, costumbres, personalidades, etc., se genera algún tipo de malestar, incomodidad y afectación puesto que no se consideran similares entre ellos (Sternberg, 2000). En consonancia con lo mencionado, Romero et al. (2017) evidencia que las similitudes entre las filosofías de vida de los cónyuges influyen en el ánimo y el desempeño diario de la persona.

Cuando los conflictos se generan por las actividades que realiza la pareja y la desconfianza, hay mayor afectación en el Rol emocional y función física y menos vitalidad se percibe, dado que la persona se siente insegura por lo que hace su compañero dentro y fuera de la relación, trayendo consigo alteraciones en sus emociones y las actividades que realiza, disminuyendo su energía y su vigor.

Cuando el motivo del conflicto es por cuestiones sexuales menos dificultades se presentan en la función física. En discrepancia con esto, 
se podría decir que al presentar dificultades en el tópico sexual más afectaciones en las respuestas físicas y motoras habrá, puesto que la conducta sexual satisfactoria en la pareja permite experimentar pasión, sentimientos enriquecedores y que potenciar la personalidad, la comunicación, además de ser una fuente de bienestar físico, psicológico, intelectual y espiritual (Planned Parenthood Federation of America, [PPFA] 2007).

En las correlaciones entre los motivos y la importancia del conflicto con la satisfacción con la relación se evidencia que el conflicto se relaciona negativamente con la satisfacción en cada uno de sus indicadores, afectando de manera global la variable. En este sentido, se puede decir que las parejas que presenta conflictos de manera frecuente y le dan gran importancia, son más infelices y están más insatisfechos en su relación, llevándolos en muchas ocasiones al deterioro y separación (Flores Galaz, 2011).

Más específicamente, cuando los conflictos son por la educación de los hijos, las actividades de la pareja, las actividades propias, la desconfianza, la familia política, los celos, el orden, la responsabilidad y la familia de origen menor satisfacción hay con la relación, con la atención que se recibe, el respeto, las actividades que se comparten y el cariño que se recibe, en vista de que al no compartir el tiempo libre con la pareja, los celos y la desconfianza se incrementan generando muchos más conflictos y dando una percepción de falta de compromiso y sentido de exclusividad produciendo insatisfacción en la pareja (Romero et al., 2017).

Cuando las desavenencias son por su personalidad, menos satisfacción hay con el respeto y el cariño que se recibe, relacionando la personalidad con cierto tipo de rasgos negativos, como por ejemplo violentos o desinteresados que hagan que la persona revalúe su relación (Zafra y Espartal, 2008; Garrido et al., 2017) y cuando es por el dinero y la irresponsabilidad se percibe menor satisfacción con la relación, con el respeto que se recibe y las actividades que se comparte con la pareja, puesto que estas disputas afectan la calidad de vida en pareja, tales como la convivencia entre la díada, ingresos y gastos económicos, y las conductas de afecto (Pérez Solís et al., 2016). 
Conforme a todo lo mencionado anteriormente, el presente estudio, logró identificar cuáles son los motivos de conflicto en las diferentes etapas de la pareja contribuyendo al vacío de conocimiento que había respecto al tema. Cabe señalar que a pesar de que las correlaciones presentaron puntajes bajos, los resultados son dignos de analizar y permiten dar una idea de cómo se comportan dichas variables en relación con aspectos como la salud y la satisfacción de cada persona, mostrando indicadores de prevención a través del trabajo conjunto con la pareja, de acuerdo al proceso que están atravesando. Otra limitación del estudio es los motivos del conflicto que se abordan en el instrumento utilizado, puesto que se requiere una actualización del mismo con respeto a las razones por las que las parejas pelean hoy en día.

Por otra parte, en futuras investigaciones de intervención, a mediano y largo plazo, es posible contribuir al desarrollo de estudios explicativos en el área, permitiendo encontrar su causalidad, y así, disminuir los conflictos que se generan en las diferentes etapas del ciclo de la pareja, evitando las posibles separaciones y contribuyendo a la salud física y mental de sus miembros, así como a su satisfacción con la relación. Finalmente, como recomendaciones, se propone unir las etapas de mantenimiento de hijos pequeños e hijos grandes, ya que se encontraron resultados similares entre estas dos categorías y a pesar de que en la literatura se menciona las diferencias en los procesos que se viven.

\section{Referencias}

Álvarez Ramírez, E., García Méndez, M. y Rivera Aragón, S. (2015). Satisfacción marital a través de la dinámica del conflicto y la culpa. Psicología Iberoamericana, 23(1), 48-57. Recuperado de http://www.redalyc.org/pdf/1339/133944230006.pdf

Aguilera Mochón, J. (2005). La ciencia frente a las creencias religiosas: Ciencia y religión en los albores del nuevo milenio. Ciencias sociales de la Fundación Giulia Adinolfi - Manuel Sacristán, 95(2), 125-153. Recuperado de http://www.ugr.es/-jmochon/ Opin/Opin_archivos/Cfcr.pdf 
Alzugaray, C. y García, F. (2015). Relaciones de pareja y bienestar. En M. Bilbao, D. Páez y J. C. Oyanedel (Eds.), La felicidad de los chilenos: Estudios sobre bienestar (pp.237-251). RIL editores.

Antonio, E. (2015). Estrategias de manejo de conflicto, satisfacción sexual y tiempo de casados como predictores de la satisfacción marital en mujeres morelenses (tesis de maestría). Universidad de Montemorelos, México.

Arias Galicia, L. (2003). La escala de satisfacción marital: análisis de su confiabilidad y validez en una muestra de supervisores mexicanos. Revista Internacional de Psicología, 27(1), 67-92. Recuperado de https://dialnet.unirioja.es/servlet/articulo?codigo $=3053870$

Arnaldo Ocádiz, O. (2001). Construcción y validación de un instrumento de conflicto para parejas mexicanas (tesis de licenciatura). Universidad Nacional Autónoma de México, Facultad de Psicología, México.

Carreño Meléndez, J. y Morales Carmona, F. (2016). La familia política como factor de conflictos en la pareja con esterilidad. Perinatología y Reproducción Humana, 30(2), 82-89. http://dx.doi. org/10.1016/j.rprh.2016.06.002

De la Espriella, C. (1995). Conflicto entre padre e hijos adolescentes. Suma psicológica, 2(1), 43-67. http://dx.doi.org/10.14349/ sumapsi1995.306

Díaz Morfa, J. (2003). Prevención de los conflictos de pareja. Desclée De Brouwer.

Flores Galaz, M., Díaz Loving, R., Rivera Aragón, S. y Chi Cervera, A. (2005). Poder y negociación del conflicto en diferentes tipos de matrimonio. Enseñanza e Investigación en Psicología, 10(2), 337-353. Recuperado en http://www.redalyc.org/articulo. oa? id=29210209

Flores Galaz, M. (2011). Comunicación y conflicto: ¿Qué tanto impactan en la satisfacción marital? Acta de Investigación Psicológica, 1(2), 216-232. Recuperado de http://www.scielo.org.mx/ pdf/aip/v1n2/v1n2a3.pdf 
García Higuera, J. (2002). La estructura de la pareja: implicaciones para la terapia cognitivo conductual. Clínica y Salud, 13(1), 89-125. Recuperado de http://www.redalyc.org/ pdf/1806/180618083004.pdf

Garrido, M., Jaén, P., y Domínguez, A. (2002). Relaciones de pareja y juego patológico: un estudio descriptivo a través de la Escala de Ajuste Diádico (DAS). Apuntes de Psicología, 20(1), 33-48. Recuperado de https://www.researchgate.net/ publication/28253300_Relaciones_de_pareja_y_juego_patologico_un_estudio_descriptivo_a_traves_de_la_Escala_de_ Ajuste_Diadico_DAS

Garrido, A., Reyes, A., Ortega, P., y Torres, L. (2007). La vida en pareja: un asunto a negociar. Enseñanza e Investigación en Psicologia, 12(2), 385-396. Recuperado de http://www.redalyc.org/ articulo.oa?id $=29212212$

Garrido, M., Valor, I., y Expósito, F. (2017). ¿Dejaría a mi pareja? Influencia de la gravedad de la transgresión, la satisfacción y el compromiso en la toma de decisión. Psychosocial Intervention, 26(2), 111-116. https://doi.org/10.1016/j.psi.2016.12.001

Hernández, M. (2012, 12 de marzo). Familia a raya. Enforma. Recuperado el 12 de octubre de 2018 de http://www.carmenpalaciosserres.com/docs/constelaciones/forma.pdf

Hernández, R., Fernández, C., y Baptista, P. (2006). Metodología de la investigación. McGraw-Hill Interamericana Editores.

Hidalgo, V., y Menéndez, S. (2003). La pareja ante la llegada de los hijos e hijas. Evolución de la relación conyugal durante el proceso de convertirse en padre y madre. Infancia y Aprendizaje, 26(4), 469-483. https://doi.org/10.1174/021037003322553851

Instituto Nacional de Estadística y Geografía (INEGI) (2016). Estadisticas de natalidad, mortalidad y nupcialidad. Recuperado el 21 de mayo de 2018 de http://www.beta.inegi.org.mx/temas/nupcialidad/default.html

Isaza, L. (2011). Causas y estrategias de solución de conflictos en las relaciones de pareja formadas por estudiantes universitarios. 
Psicogente, 14(26), 336-351. Recuperado de http://portal.unisimonbolivar.edu.co:82/rdigital/psicogente/index.php/psicogente Isidro, A. y Peñil, I. (2014). Rosas y espinas en las relaciones de parejas de novios: amor, expectativas y problemas. INFAD Revista de Psicología, 3(1), 385-394. Recuperado de http://www.infad.eu/ RevistaINFAD/OJS/index.php/IJODAEP/article/view/516

Mirecki, R. M., Brimhall, A. S., y Bramesfeld, K. D. (2013). Communication during conflict: Differences between individuals in first and second marriages. Journal of Divorce and Remarriage, 54(3), 197-213. https://doi.org/10.1080/10502556.2013.773798

Mora, M. (2015). Estrategias de afrontamiento durante el conflicto de pareja (tesis de licenciatura). Universidad Nacional Autónoma de México. Recuperado de http://132.248.9.195/ptd2015/ febrero/304094563/Index.html

Orgilés, M. y Piñedo, J. (2006). ¿Existe relación entre el abuso de drogas y la ruptura de pareja? Análisis de la percepción de ambos cónyuges sobre las causas de su separación Salud y Drogas, 6(2), 215-228. Recuperado de http://www. redalyc.org/articulo.oa?id $=83960206$

Oropeza Lozano, R., Armenta Hurtarte, C., García Arista, A., Padilla Gámez, N. y Díaz Loving, R. (2010). Validación de la escala de Evaluación de Relaciones en la población mexicana. Psicología Iberoamericana, 18(2), 56-65. Recuperado de http://www. redalyc.org/pdf/1339/133915921007.pdf

Peńa, F. (2010, 1 de noviembre). Síndrome del nido vacío: cuando los hijos "vuelan" de casa. Revista Consumer. Recuperado el 17 de octubre de 2018 de http://revista.consumer.es/web/ es/20101101/pdf/salud.pdf

Pérez Solís, G., Dávalos Romo, M. T. y Rentería Conseción, J. (2016). Grado de satisfacción marital en relación a factores sociodemográficos. Revista Digital Internacional de Psicología y Ciencia Social, 2(2), 171-187. Recuperado de cuved.unam.mx/revistas/ index.php/rdpcs/article/download/68/196 
Planned Parenthood Federation of America. (2007). Los beneficios de la expresión sexualpara la salud. Recuperado el 17 de octubre de 2018 de https://www.plannedparenthood.org/files/8513/9980/7841/ LosBeneficiosDeLaExpresionSexualParaLaSalud_07-07_translated_08-07.pdf

Ramírez, A. (2004). Conflictos entre padres y desarrollo de los hijos. Convergencia. Revista de Ciencias Sociales, 11(34), 171-182. http://www.redalyc.org/articulo.oa?id=10503407

Ripoll Núñez, K., Martínez Arrieta, K. y Giraldo Gallo, A. (2013). Decisiones sobre crianza de los hijos en familias reconstituidas. Revista Colombiana de Psicología, 22(1), 163-177.

Rivera, D., Cruz, C. y Muñoz, C. (2011). Satisfacción en las relaciones de pareja en la adultez emergente: el rol del apego, la intimidad y la depresión. Terapia Psicólogica, 29(1), 77-83. http://dx.doi. org/10.4067/S0718-48082011000100008

Rivero, N., Martínez, A. y Iraurgi, I. (2011). El papel funcionamiento y la comunicación familiar en los síntomas psicosomáticos. Clínica y Salud, 22(2), 175-186. Recuperado de http://www. redalyc.org/articulo.oa?id=180621194006

Rodas López, M. (2018). Adaptación emocional y divorcio (tesis de licenciatura). Universidad Rafael Landívar, México.

Rodríguez, J. (2015). Detonantes de la calidad en la relación, tácticas ante el conflicto y las estrategias de co-regulación emocional (tesis de licenciatura). Universidad Nacional Autónoma de México.

Rodríguez, P. (2013). Los estilos de poder y el manejo de conflicto: una perspectiva de la satisfacción marital (tesis de licenciatura). Universidad Nacional Autónoma de México, Facultad de Psicología, México.

Romero, A., Galicia, V., y Del Castillo, A. (2017). La satisfacción con la relación de pareja en la actualidad. Educación y Salud, 5(10). Recuperado de https://www.uaeh.edu.mx/scige/boletin/icsa/ n10/e9.html

Ruiz, J. (2008). El concepto de familia política: notas para una discusión. Sociológica, (23)66, 175-186. Recuperado de http:// biblioteca.ues.edu.sv/revistas/10702480-8.pdf 
Sánchez Aragón, R. (1995). El amor y la cercanía en la satisfacción de la pareja a través del ciclo de la vida (tesis de maestría). Universidad Nacional Autónoma de México.

Sánchez Aragón, R. (2016). La pareja romántica en México. Desentrañando su naturaleza comunicativa y emocional. Universidad Nacional Autónoma de México.

Sánchez Aragón, R., García Meraz, M. y Martínez Trujillo, B. (2017). Encuesta de Salud SF-36: Validación en tres contextos culturales de México. Revista Iberoamericana de Diagnóstico y Evaluación - e Avaliação Psicológica. RIDEP, 45(3), 5-16. http://dx.doi. org/10.21865/RIDEP45.3.01

Sánchez Aragón, R. (2018). Afectividad y co-regulación en la pareja: validación de un inventario y variaciones a través del ciclo vital. Revista Psicologia e Eduçao (On-Line), 1(1), 58-69. Recuperado http://psicologiaeeducacao.ubi.pt/Files/Other/Artigos\%20 OnLine/2018/V1N1\%20online/6.\%20V1N1online2018.pdf

Sanmartín, B. (2014). El impacto del divorcio en la relación de pareja de los hijos: un meta-análisis (tesis de maestría). Universidad de Santiago de Compostela, Facultad de Psicología, España.

Smith, E. y Clark, S. (2017). Variation in the link between parental divorce and children's health disadvantage in low and high divorce settings. Population Health, 3, 473-486. http://dx.doi. org/10.1016/j.ssmph.2017.04.004

Soto Estrada, G., Moreno Altamirano, L., Pahua Díaz, D. (2016). Panorama epidemiológico de México, principales causas de morbilidad y mortalidad. Revista de la Facultad de Medicina de la UNAM, 59(6), 8-22. Recuperado de http://www.medigraphic. $\mathrm{com} / \mathrm{pdfs} /$ facmed/un-2016/un166b.pdf

Sternberg, R. J. (2000). La experiencia del amor: La evolución de la relación amorosa a lo largo del tiempo. Paidós.

Subsecretaría de Integración y Desarrollo del Sector Salud (SIDSS). (2015). Informe sobre la salud de los mexicanos 2015. Diagnóstico general de la salud poblacional. Recuperado el 4 de octubre de 2018 de www.dged.salud.gob.mx/contenidos/dedss/ issm2015.html 
Silva, D. y Vázquez, C. (2016). Poder y conflicto: factores detonantes de una infidelidad en una relación de pareja (tesis de licenciatura). Universidad Nacional Autónoma de México.

Tapia, L., Poulsen, G., Armijo, I., Pereira, X., y Sotomayor, P. (2009). Resolución de entrampes en parejas en conflicto: aproximaciones desde las parejas y los terapeutas. Revista Argentina de Clínica Psicológica, 18(2), 101-114. Recuperado de http://www. redalyc.org/pdf/2819/281921792001.pdf

The Worldwide Independent Network/Gallup International Association (WIN/GIA). (2015). Losing our religion? Two thirds of people still claim to be religious. Recuperado el 4 de octubre de 2018 de https://www.eltelegrafo.com.ec/images/eltelegrafo/ Sociedad/2015/23-04-15-sociedad-Gallup-religion.pdf

Wieden, J. (2018). The impact of using intimacy rituals and romantic attachment on satisfaction among romantic couples (tesis doctoral). Alliant International University. San Francisco.

Willi, J. (2002) La pareja humana: relación y conflicto. Madrid: Ediciones Morata.Recuperadoel12demayode2018dehttps://books.google. com.mx/books?id=7eLUd-N_VPsCyprintsec=frontcoveryhl=es ysource $=$ gbs_ge_summary_rycad $=0 \# \mathrm{v}=$ onepageyqyf $=$ false

Zafra, E. y Espartal, N. (2008). Relación entre cultura del honor, celos y Satisfacción en la pareja. Boletín de Psicologia, 94, 7-22. Recuperado https://www.researchgate.net/ publication/28250362_Relacion_entre_cultura_del_honor_ celos_y_satisfaccion_en_la_pareja

Zazueta, E., y Sandoval, S. (2013). Concepciones de género y conflictos de pareja. Un estudio con parejas pobres heterosexuales en dos zonas urbanas de Sonora. Culturales, 1(2), 91-118. Recuperado de http://www.redalyc.org/articulo.oa?id=69429400003

Recibido: 2019-02-22

Revisado: 2021-08-02

Aceptado: 2021-11-17 